University of Nebraska - Lincoln

DigitalCommons@University of Nebraska - Lincoln

March 2005

\title{
Um34 in selenocysteine tRNA is required for the expression of stress-related selenoproteins in mammals
}

\author{
Bradley A. Carlson \\ National Institutes of Health, Bethesda, MD \\ Xue-Ming Xu \\ National Institutes of Health, Bethesda, MD \\ Vadim N. Gladyshev \\ University of Nebraska-Lincoln, vgladyshev@rics.bwh.harvard.edu \\ Dolph L. Hatfield \\ National Institutes of Health, Bethesda, MD
}

Follow this and additional works at: https://digitalcommons.unl.edu/biochemgladyshev

Part of the Biochemistry, Biophysics, and Structural Biology Commons

Carlson, Bradley A.; Xu, Xue-Ming; Gladyshev, Vadim N.; and Hatfield, Dolph L., "Um34 in selenocysteine tRNA is required for the expression of stress-related selenoproteins in mammals" (2005). Vadim Gladyshev Publications. 57.

https://digitalcommons.unl.edu/biochemgladyshev/57

This Article is brought to you for free and open access by the Biochemistry, Department of at DigitalCommons@University of Nebraska - Lincoln. It has been accepted for inclusion in Vadim Gladyshev Publications by an authorized administrator of DigitalCommons@University of Nebraska - Lincoln. 


\section{Um34 in selenocysteine tRNA is required for the expression of stress-related selenoproteins in mammals}

Bradley A. Carlson, Xue-Ming Xu, Vadim N. Gladyshev, and Dolph L. Hatfield

\section{Abstract}

Selenium is an essential micronutrient in the diet of mammals and has many health benefits. Selenium-containing proteins are responsible for most, if not all, of these benefits. This element is incorporated into protein as selenocysteine ( $\mathrm{Sec})$, the $21^{\text {st }}$ amino acid in the genetic code. There are two species of Sec tRNA in mammalian cells that differ by a single 2'-O-hydroxymethyl group on the ribosyl moiety at position 34 (Um34). The relationship between this modification and selenoprotein synthesis was examined in mice in which the wild type Sec tRNA gene was replaced with a mutant Sec tRNA transgene incapable of forming Um34. This mouse line did not express several stress-related selenoproteins, whereas the levels of several selenoproteins thought to serve housekeeping functions were normal. This novel form of protein regulation occurred at the translational level. The Um34 modification in Sec tRNA, therefore, plays a crucial role in regulating the expression of a subset of mammalian selenoproteins and is a requisite for the synthesis of several stress-related selenoproteins.

\section{Introduction}

Selenium is a vital component in the diet of humans and other mammals and has numerous health benefits. It was reported that this element decreases the incidence of certain forms of cancer, and alleviates heart disease and other cardiovascular and muscle anomalies (Hatfield 2001). Furthermore, selenium has been observed to inhibit viral expression, delay the aging process, slow the progression of AIDS in HIV-positive patients and it has roles in mammalian development, male reproduction and immune function (Hatfield 2001). The underlying mechanisms of how selenium promotes these benefits are just beginning to be understood. The available evidence strongly indicates that selenoproteins are the responsible agents (Diwadkar-Navsariwala and Diamond 2004). There are 25 selenoprotein genes in the human genome and 24 in the genomes of rodents (Kryukov et al. 2003). The functions of less than half of the selenoprotein gene products have been characterized

Topics in Current Genetics, Vol. 12

H. Grosjean (Ed.): Fine-Tuning of RNA Functions by Modification and Editing DOI 10.1007/b106652 / Published online: 20 January 2005

(C) Springer-Verlag Berlin Heidelberg 2005 
Selenium is incorporated into protein as the $21^{\text {st }}$ amino acid, selenocysteine (Sec), in the genetic code (Hatfield and Gladyshev 2002). The codeword for Sec is UGA and Sec is biosynthesized on its tRNA (designated tRNA ${ }^{[\mathrm{Ser}] \mathrm{Sec}}$ ) following aminoacylation of the tRNA with serine by seryl-tRNA synthetase. The reason UGA can be used as a Sec codon instead of its usual role as a termination codon is the presence of a stem-loop structure in the 3'-untranslated region of eukaryotic selenoprotein mRNAs designated as the Sec insertion sequence or SECIS element (Low and Berry 1996). The machinery involved in the insertion of Sec into protein includes several additional specific factors such as an elongation factor and a SECIS binding protein (reviewed in Driscoll and Copeland 2003). Interestingly, none of the known factors involved in the insertion of Sec into protein appear to have a regulatory role in translation of selenoprotein mRNAs. However, as described in the present review, base modification in Sec tRNA ${ }^{[\mathrm{Ser}] \mathrm{Sec}}$ (for review, see Hatfield and Gladyshev 2002) plays a key role in determining which selenoprotein mRNAs are translated.

\section{Sec tRNA ${ }^{[\operatorname{Ser}] \operatorname{Sec}}$}

Sec tRNA ${ }^{[\mathrm{Ser}] \mathrm{Sec}}$ has many unique characteristics as it is the longest eukaryotic tRNA sequenced to date and it is highly undermodified compared to other tRNAs (Hatfield and Gladyshev 2002). It has only four modified bases and biosynthesis of the base modifications have been characterized in Xenopus oocytes (Choi et al. 1994; Sturchler et al. 1994). The Sec tRNA ${ }^{[\mathrm{Ser}] \mathrm{Sec}}$ population in mammals consists of two isoforms that differ from each other by a single methyl modification on the ribosyl moiety at position 34 (Um34; Fig. 1). Addition of the methyl group is a highly specialized last step in maturation and determines both the structure and function of tRNA ${ }^{[\mathrm{Ser}] \mathrm{Sec}}$ (reviewed in Hatfield and Gladyshev 2002). This methylation is dependent on the prior synthesis of four other modified bases and on an intact tertiary structure, whereas synthesis of the other modified bases is less stringently connected to primary and tertiary structure (Kim et al. 2000). Furthermore, methylation of U34 is enhanced by enriched selenium levels (reviewed in Hatfield and Gladyshev 2002) and its presence dramatically affects secondary and tertiary structure (Diamond et al. 1993). In addition, as shown in Figure 1, the occurrence of the Um34 isoform correlates with the expression of several selenoproteins (see also Chittum et al. 1997; Moustafa et al. 2001; and below). Recently, the selenium-induced, Sec tRNA ${ }_{\text {merum }}^{[\mathrm{Ser}] \mathrm{Sec}}$ isoform has been reported to have a specialized role in selenoprotein biosynthesis in that it is likely the major isoacceptor used in expressing this protein class (Jameson and Diamond 2004). One of our major goals, therefore, has been to better understand the role of this methyl group in selenoprotein expression.

Changing $\mathrm{A}$ to $\mathrm{G}$ at position 37 results in a tRNA ${ }^{[\mathrm{Ser}] \mathrm{Sec}}$ that lacks both isopentenyladenosine ( $\left.\mathrm{i}^{6} \mathrm{~A}\right)$ at this position $\left(\mathrm{i}^{6} \mathrm{~A} 37\right)$ and $\mathrm{Um} 34$ (Kim et al. 2000). This observation provided an opportunity to generate a mutant $\mathrm{RNA}^{[\mathrm{Ser}] \mathrm{Sec}}$ without this highly specialized methyl group and examine its role in selenoprotein synthesis. 


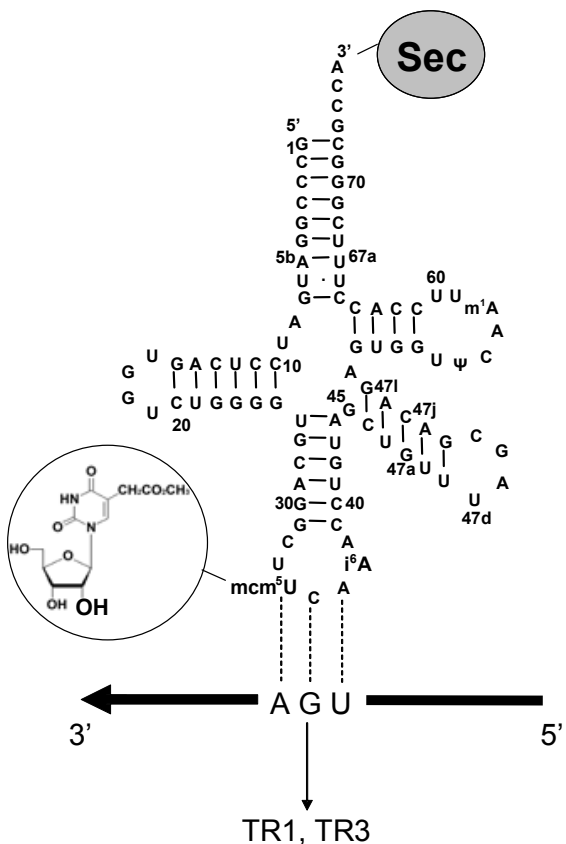

TR1, TR3

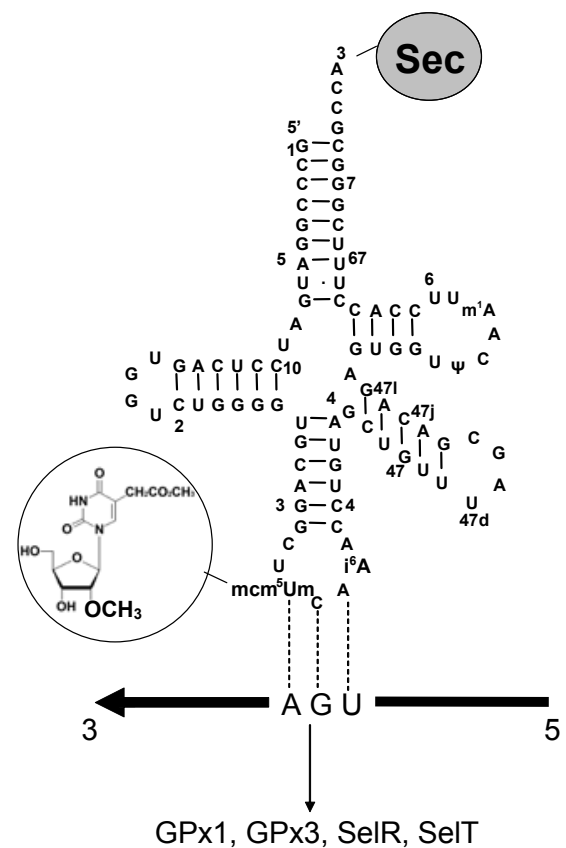

Fig. 1. Secondary structures of the two Sec tRNA ${ }^{[\mathrm{Ser}] \mathrm{Sec}}$ isoforms that correspond to the selenoproteins they synthesize. Both isoforms are 90 nucleotides in length and contain four modified nucleosides as follows: at position 34, methylcarboxylmethyl-5'-uridine $\left(\mathrm{mcm}^{5} \mathrm{U}\right.$; left isoform) or methylcarboxylmethyl-5'-uridine-2'-O-methylribose $\left(\mathrm{mcm}^{5} \mathrm{Um}\right.$; right panel), position 37 , isopentenyladenosine $\left(i^{6} \mathrm{~A}\right)$, position 55 , pseudouridine $(\Psi)$, and position 58,1-methyladenosine $\left(\mathrm{m}^{1} \mathrm{~A}\right)$. Structures of $\mathrm{mcm}^{5} \mathrm{U}$ and $\mathrm{mcm}^{5} \mathrm{Um}$ are shown within the circles immediately to the left of position 34 wherein the 2'-O-hydroxy and 2'-Ohydroxymethyl positions are enlarged and bolded. Selenoproteins specifically expressed by both isoforms from selenoprotein mRNA encoding a UGA codon (drawn in the 3' to 5' direction) are shown at the bottom of the figure.

\section{Generation of mouse models}

Selenoproteins are the only known class of proteins that are dependent on the presence of a single tRNA, tRNA ${ }^{[\mathrm{Ser}] \mathrm{Sec}}$, for their expression. This unique characteristic of selenoprotein biosynthesis provides us with a novel means of perturbing their expression. By altering tRNA ${ }^{[\mathrm{Ser}] \mathrm{Sec}}$ levels and making tRNA ${ }^{[\mathrm{Ser}] \mathrm{Sec}}$ mutants, we have generated models for elucidating the cellular roles of selenoproteins as well as their roles in health (Moustafa et al. 2003). These models include a transgenic mouse line carrying either a wild type $\mathrm{tRNA}^{[\mathrm{Ser}] \mathrm{Sec}}$ transgene (designated trsp $p^{t}$ ) or a mutant tRNA ${ }^{[\mathrm{Ser}] \mathrm{Sec}}$ transgene (designated $t r s p^{t} \mathrm{i}^{6} \mathrm{~A}^{-}$) that lacks $i^{6} \mathrm{~A} 37$ and 
Table 1. Rescue of selenoprotein expression in Sec tRNA transgenic-knockout mice. ${ }^{1}$

\begin{tabular}{ccccc}
\hline Selenoprotein $^{2}$ & \multicolumn{3}{c}{ Tissue $^{3}$} & \multicolumn{3}{c}{ Western $^{4}$} \\
\hline & & trsp & trsp $^{\mathrm{t}}$ & trsp $^{\mathrm{t}}$ 16 \\
GPx1 & Liver & +++ & +++ & - \\
& Kidney & +++ & +++ & - \\
GPx2 & Intestine & +++ & ++++ & + \\
SelR & Liver & +++ & +++ & - \\
& Kidney & +++ & +++ & - \\
SelT & Liver & +++ & +++ & - \\
TR1 & Liver & +++ & +++ & +++ \\
& Kidney & +++ & +++ & +++ \\
TR3 & Liver & +++ & +++ & +++ \\
& Kidney & +++ & +++ & +++ \\
& Brain & +++ & +++ & +++ \\
\hline
\end{tabular}

${ }^{1}$ Mouse lines are $t r s p^{f l}$ (wild type, homozygous for floxed $t r s p^{f l}$ [Kumaraswamy et al. 2003]), $\operatorname{trsp}^{t}$ (homozygous for wild type $\operatorname{trsp}^{t}$ transgene [Moustafa et al. 2001] and homozygous $\Delta t r s p$ knockout [Kumaraswamy et al. 2003]) and $t r s p^{t} \mathrm{i}^{6} \mathrm{~A}^{-}$(homozygous for mutant $t r s p^{t} \mathrm{i}^{6} \mathrm{~A}^{-}$transgene [Moustafa et al. 2001] and homozygous trsp knockout [Kumaraswamy et al. 2003]). Labeling of mice with ${ }^{75} \mathrm{Se}$ and analysis of the resulting labeled selenoproteins from various tissues (Moustafa et al. 2001; Kumaraswamy et al. 2003; Carlson et al. 2004a and 2004b) demonstrated that several selenoproteins were fully (thioredoxin reductase 1 and 3) or partially (glutathione peroxidase 4, selenoprotein 15 and selenoprotein $\mathrm{P}$ ) rescued, while others (GPx1 and GPx3) were poorly rescued as discussed in the text.

${ }^{2}$ Selenoproteins are: GPx1 and GPx2, glutathione peroxidase 1 and 2; SelR, selenoprotein R; SelT, selenoprotein T; and TR1 and TR3, thioredoxin reductase 1 and 3 (for further details on these selenoproteins, see Kryukov et al. 2003).

${ }^{3}$ Extracts were made from tissues shown and prepared for western blotting, and western analysis carried out as described in Moustafa et al. (2001) and Kumaraswamy et al. (2003). ${ }^{4}$ Antibodies against GPx1 were obtained from Qichang Shen and GPx2 from Regina Brigelius-Flohé, and those against SelR, SelT, TR1, and TR3 were from our laboratories.

Um34 (Moustafa et al. 2001). In addition, a very useful model for elucidating the roles of selenoproteins in health was generated by preparing a conditional knockout mouse line wherein trsp is flanked by loxP sites (designated $t r s p^{f l}$ ) and its targeted removal is dependent on loxP-Cre technology (Kumaraswamy et al. 2003). This mouse line has permitted us to selectively remove trsp in different tissues and examine in more detail the role of selenoproteins in development and health. Finally, a standard knockout mouse line carrying a deletion of trsp (designated $\Delta$ trsp) has been prepared (Bösl et al. 1997; Kumaraswamy et al. 2003). Although this mouse line is embryonic lethal, it has provided a means of rescuing selenoprotein expression with wild type or mutant Sec tRNA ${ }^{[\mathrm{Ser}] \mathrm{Sec}}$ transgenes. 


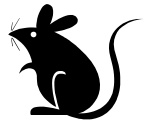

Genotype:

trsp/ $\Delta$ trsp $\operatorname{trsp}{ }^{\mathrm{i}} \mathrm{i} \mathrm{A} \mathrm{A}-/ \operatorname{trsp} \mathrm{t}^{\mathrm{i}} \mathrm{6 \textrm {A }}$

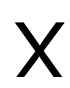
trspti6A-/ trspti6A- trsp/ $\Delta$ trsp

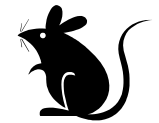

Genotype:

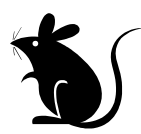

Genotype: trsp/trsp trspti6A-/ trsp ${ }^{t} i 6 \mathrm{~A}$

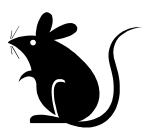

Genotype: trsp/ $\Delta$ trsp $\operatorname{trsp} p^{t} \mathrm{i} \mathrm{A}^{-} / \operatorname{trsp}{ }^{t} \mathrm{i} 6 \mathrm{~A}$

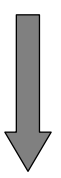

Fig. 2. Scheme of mouse matings for rescuing selenoprotein expression. Mice that were heterozygous for the wild type (trsp) and knockout $(\Delta t r s p)$ tRNA ${ }^{[\mathrm{Ser}] \mathrm{Sec}}$ genes and homozygous for mutant $\mathrm{i}^{6} \mathrm{~A} 37$ transgenes $\left(\operatorname{trs} p^{t} \mathrm{i}^{6} \mathrm{~A}^{-}\right)$were obtained as described (Kumaraswamy et al. 2003) and mated as shown yielding the rescued mice that were homozygous for $\Delta$ trsp and $\operatorname{trsp} p^{t} \mathrm{i}^{6} \mathrm{~A}^{-}$. Mice that were rescued with the wild type $t r s p^{t}$ transgene were obtained in the same manner as shown in the figure for the mutant $\operatorname{trs} p^{t} 16 \mathrm{~A}^{-}$transgene. These mice were analyzed for selenoprotein expression by ${ }^{75} \mathrm{Se}$-labeling and western blotting and the expression data are given in Table 1.

\subsection{Selective rescue of selenoprotein expression}

By mating mice that are heterozygous for trsp knockout $(\Delta \operatorname{trsp})$ with transgenic mice that are homozygous for $t r s p^{t}$ or $\operatorname{trsp}^{t} i^{6} \mathrm{~A}^{-}$transgenes, we have been able to generate a mouse line that is homozygous for either wild type $\operatorname{trsp} p^{t}$ or $\operatorname{trsp}^{t} \mathrm{i}^{6} \mathrm{~A}^{-}$ (Carlson et al. 2004b). Matings among the latter mouse line yielded mice that were dependent on the transgenes for survival (Fig. 2).

Transgenic-knockout mice in which selenoprotein expression has been rescued with $\operatorname{trsp}^{t}$ synthesize selenoproteins in normal amounts (see Table 1). However, transgenic-knockout mice in which selenoprotein expression has been rescued with $\operatorname{trsp}^{t} \mathrm{i}^{6} \mathrm{~A}^{-}$synthesize many, but not all selenoproteins (see legend 1 to Table 1 and last column on the right in the Table). Interestingly, GPx1, GPx2, GPx3, SelR, and SelT are either not rescued or are poorly rescued (Table 1 and legend). The known functions of these selenoproteins suggest that they are involved with stressrelated phenomena (Kryukov et al. 2003).

In addition, administering ${ }^{75}$ selenium to the transgenic-knockout mice and analyzing the resulting labeled selenoprotein population (see Carlson et al. 2004b and 
references therein) in various tissues (e.g. liver, kidney, heart, testis, intestine, plasma, and spleen) confirmed the absence of the non-rescued proteins identified in Table 1 (see also table legend and Carlson et al. 2004b). Furthermore, northern analysis of mRNA levels of the non-rescued selenoproteins demonstrated that they were expressed in sufficiently high levels for their expression, but the corresponding selenoproteins were not expressed. Thus, the observed phenomenon appears to be a defect at the translation step.

\section{Discussion and concluding remarks}

The results in Table 1 demonstrate that base modification(s) in the anticodon loop of $\mathrm{tRNA}^{[\mathrm{Ser}] \mathrm{Sec}}$ is (are) involved in selenoprotein expression. The strain of trans-

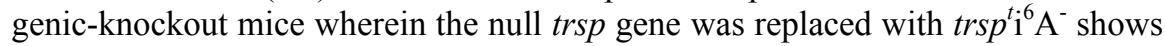
that several selenoproteins were poorly rescued by the mutant transgene, whereas several additional selenoproteins were expressed in normal amounts. Since the mutant isoform of tRNA ${ }^{[\mathrm{Ser}] \mathrm{Sec}}$ lacks both $\mathrm{i}^{6} \mathrm{~A} 37$ and Um34, questions may be asked as to which modification, or whether an interplay between both modifications, influence(s) selenoprotein synthesis in the manner observed in this study. Clearly, the mutant isoform efficiently supports the synthesis of housekeeping selenoproteins, such as TR1 and TR3 (see Table 1 and Carlson et al. 2004b), demonstrating that this isoform is used effectively in protein synthesis. In fact, it supports the synthesis of those selenoproteins that the non-Um34 isoform, tRNA $^{[\mathrm{Ser}] \mathrm{Sec}}$ memU, synthesizes in mammalian cells and tissues (Chittum et al. 1997; Moustafa et al. 2001; Carlson et al. 2004b). The critical modification that is missing from the Sec tRNA ${ }^{[\mathrm{Ser}] \mathrm{Sec}}$ population normally found in mammalian cells is Um34. Not only does the absence of Um34 correlate with a decrease in the expression of several stress-related selenoproteins, but the synthesis of Um34 on $\mathrm{tRNA}^{[\mathrm{Ser}] \mathrm{Sec}}$ is also a selenium dependent reaction. Selenium deficient mice have reduced amounts of this methylated isoform, and in addition have reduced amounts of several of the selenoproteins identified herein (reviewed in Hatfield and Gladyshev 2002). Therefore, a strong correlation exists between similar phenotypes observed in selenium deficient mice and in mice carrying $i^{6} \mathrm{~A}^{-} t r s p$. Furthermore, as noted in section 15.2, the presence of this methyl group in $\mathrm{tRNA}^{[\mathrm{Ser}] \mathrm{Sec}}$ is a highly specialized event in tRNA ${ }^{[\mathrm{Ser}] \mathrm{Sec}}$ structure and function. Finally, we have identified a factor that influences U34m formation (unpublished results). Knockdown of this factor in mammalian cells using RNAi technology demonstrates that the resulting phenotype has reduced levels of GPx1 as is observed in the transgenic-knockout mice described herein (see also Carlson et al. 2004b). Overall, the evidence strongly supports a major role of Um34 in the synthesis of selenoproteins that are involved in stress-related phenomena. Furthermore, the data suggest that the observed loss in selenoprotein expression is unlikely due to the absence of $i^{6} \mathrm{~A}$ or to an interplay between $\mathrm{i}^{6} \mathrm{~A}$ and Um34.

An examination of many different parameters of selenoprotein mRNAs (summarized in Kryukov et al. 2003) such as nucleotide context of the UGA Sec 
codon, SECIS element class and location of the UGA Sec codon within the open reading frame has not revealed any clear pattern that would explain why Um34 may be responsible for the expression of only certain selenoproteins. The precise mechanism of how Um34 is responsible for the synthesis of a subset of selenoproteins must await further investigation. It should be noted, however, that this study provides the first example of the translation of several proteins being dependent on the recoding of a nonsense codeword involving Um34 and provides a novel role of tRNA in protein expression (see also Carlson et al. 2004b).

\section{References}

Bösl MR, Takaku K, Oshima M, Nishimura S, Taketo MM (1997) Early embryonic lethality caused by targeted disruption of the mouse selenocysteine tRNA gene (Trsp). Proc Natl Acad Sci USA 94:5531-5534

Carlson BA, Novoselov SV, Kumaraswamy E, Lee BJ, Anver MR, Gladyshev VN, Hatfield DL (2004a) Specific excision of the selenocysteine tRNA ${ }^{[\mathrm{Ser}] \mathrm{Sec}}($ trsp $)$ gene in mouse liver demonstrates an essential role of selenoproteins in liver function. J Biol Chem 279:8011-8017

Carlson BA, Xu Xue-Ming, Gladyshev VN, Hatfield DL (2004b) Selective rescue of selenoprotein expression in mice lacking a highly specialized methyl group in selenocysteine tRNA. J Biol Chem (in press)

Chittum HS, Hill KE, Carlson BA, Lee BJ, Burk RF, Hatfield DL (1997) Replenishment of selenium deficient rats with selenium results in redistribution of the selenocysteine tRNA population in a tissue specific manner. Biochim Biophys Acta 1359:25-34

Choi IS, Diamond AM, Crain PF, Kolker JD, McCloskey JA, Hatfield, DL (1994) Reconstitution of the biosynthetic pathway of selenocysteine tRNAs in Xenopus oocytes. Biochem 33:601-605

Diamond AM, Choi IS, Crain PF, Hashizume T, Pomerantz SC, Cruz R, Steer CJ, Hill KE, Burk RF, McCloskey JA, Hatfield DL (1993) Dietary selenium affects methylation of the wobble nucleoside in the anticodon of selenocysteine tRNA[Ser]Sec. J Biol Chem 268:14215-14223

Diwadkar-Navsariwala V, Diamond AM (2004) The link between selenium and chemoprevention: a case for selenoproteins. J Nutr 134:2899-2902

Driscoll DM, Copeland PR (2003) Mechanism and regulation of selenoprotein synthesis. Annu Rev Nutr 23:17-40

Hatfield DL (2001) Selenium: Its Molecular Biology and Role in Human Health. Kluwer Academic Publishers, Norwell, MA

Hatfield DL, Gladyshev VN (2002) How selenium has altered our understanding of the genetic code. Mol Cell Biol 22:3565-3576

Jamenson RR, Diamond AM (2004) A regulatory role for Sec tRNA[Ser]Sec in selenoprotein synthesis. RNA 10:1142-1152

Kim LK, Matsufuji T, Matsufuji S, Carlson BA, Kim SS, Hatfield DL, Lee BJ (2000) Methylation of the ribosyl moiety at position 34 of selenocysteine tRNA[Ser]Sec is governed by both primary and tertiary structure. RNA 6:1306-1315

Kryukov GV, Castellano S, Novoselov SV, Lobanov AV, Zehtab O, Guigo R, Gladyshev VN (2003) Characterization of mammalian selenoproteomes. Science 300:1439-1443 
Low SC, Berry MJ (1996) Knowing when not to stop: selenocysteine incorporation in eukaryotes. Trends Biochem Sci 21:203-208

Kumaraswamy E, Carlson BA, Morgan F, Miyoshi K, Robinson GW, Su D, Wang S, Southon E, Tessarollo L, Lee BJ, Gladyshev VN, Hennighausen L, Hatfield DL (2003) Selective removal of the selenocysteine tRNA[Ser]Sec gene (Trsp) in mouse mammary epithelium. Mol Cell Biol 23:1477-1488

Moustafa ME, Carlson BA, El-Saadani MA, Kryukov GV, Sun QA, Harney JW, Hill KE, Combs GF, Feigenbaum L, Mansur DB, Burk RF, Berry MJ, Diamond AM, Lee BJ, Gladyshev VN, Hatfield DL (2001) Selective inhibition of selenocysteine tRNA maturation and selenoprotein synthesis in transgenic mice expressing isopentenyladenosinedeficient selenocysteine tRNA. Mol Cell Biol 21:3840-3852

Moustafa ME, Kumaraswamy E, Zhong N, Rao M, Carlson BA, Hatfield DL (2003) Models for assessing the role of selenoproteins in health. J Nutr 133:2494S-2496S

Carlson, Bradley A.

Molecular Biology of Selenium Section, Laboratory of Cancer Prevention, Center for Cancer Research, National Cancer Institute, National Institutes of Health, Bethesda, MD 20892 USA

Gladyshev, Vadim N.

Department of Biochemistry, University of Nebraska, Lincoln, NE 68588 USA

Hatfield, Dolph L.

Molecular Biology of Selenium Section, Laboratory of Cancer Prevention, Center for Cancer Research, National Cancer Institute, National Institutes of Health, Bethesda, MD 20892 USA

hatfield@dc37a.nci.nih.gov

$\mathrm{Xu}$, Xue-Ming

Molecular Biology of Selenium Section, Laboratory of Cancer Prevention, Center for Cancer Research, National Cancer Institute, National Institutes of Health, Bethesda, MD 20892 USA 